\title{
Adults Rule? Children, Advocacy and Complaints to Social Services
}

\author{
Andrew Pithouse* \\ Childhood Research Group, School of Social Sciences, Cardiff University, Wales \\ Anne Crowley \\ Children's Research and Policy Consultant, Red Kite Consultancy, Cardiff, Wales
}

This article sets out results from a Welsh Assembly government-funded study of complaints involving children and their use of advocacy services commissioned by local authorities in Wales. As this is the first study of its kind in Wales there is no baseline against which to compare the findings, hence we discuss the data in the context of a wider UK research literature and in relation to two key themes. These are (a) the number of complaints to social services involving children and the main characteristics of these complaints, particularly the involvement of an advocacy service and (b) the views of children about making a complaint and their experience of independent advocacy. The article reveals the adult-dominated nature of the children's complaints system and the limited involvement of advocacy in supporting children who make a complaint. The pressing need for a more child-focused approach that gives authentic voice to children and their rights is the key conclusion drawn from the evidence gathered in this study.

\section{Introduction}

The article focuses upon complaints to social services in Wales led by or on behalf of children and young people and the role of children's advocacy, funded by local government, whose core function is providing independent support to children. For purposes of economy, we use the term 'children' throughout much of the paper but mean this to include young people as well. We do not include in our discussion education, health or a multitude of other services that may have, as some aspect of their remit to children, a role akin to advocacy and/or other modes of representation or indeed may be the subject of complaints by children, although we do so in our original study (Pithouse and others, 2005).

Key investigations have shaped the policy terrain in which complaints and advocacy now operate in Wales. Thus, reports by Carlile (2002); Jones (1999); Waterhouse (2000) and the Children's Commissioner for Wales (Clarke, 2003) have all noted the critical role of listening to children and taking their concerns seriously to provide effective safeguarding. Concern that vulnerable children were not listened to when wishing to make a complaint (see Children's Rights Development Unit, 1994; Utting, 1997; Waterhouse, 2000) helped inform changes to the Children Act 1989, introduced in the Adoption and Children Act 2002, that provide children in need and care leavers with a statutory right to advocacy when intending to make a complaint (see Welsh Assembly Government, 2003a).

(C) 2006 The Author(s)

Journal compilation ㄷ 2006 National Children's Bureau 
In consequence, an element of Welsh Assembly government funding to local authorities (introduced in 2001/2002) is intended to support the commissioning of independent advocacy by all 22 unitary councils. Currently, children's advocacy is commissioned from five voluntary sector providers (most are UK children's charities) that serve one or more authorities across Wales. The Welsh Assembly government (as in England, see Department of Health, 2003) has set out a definition of what it means by advocacy in National Standards for the Provision for Children's Advocacy (Welsh Assembly Government, 2003b). The standards are issued under Section 7(1) of the Local Authority Social Services Act 1970 requiring local authorities with social services functions to act under the guidance of the Welsh Assembly government. The National Standards cover advocacy for children and young people (including those leaving care) up to the age of 21. The Standards recognise that children are not merely 'adults in training' but people able to form and express opinions, participate in decision-making processes and influence solutions (Welsh Assembly Government, 2003b). They set a basic level that children and young people can expect from professionals providing advocacy services. While all advocacy providers in Wales endorse the Standards and seek to inform their services accordingly, the critical issue is whether children and young people can access these. As we shall see, relatively few children's complaints that we examined involved professional advocacy.

\section{Models of advocacy}

An extensive literature which cannot be addressed here suggests that advocacy is generally agreed to be a process of ensuring another's voice is heard, and enabling another to speak up or speaking for another, and that the objective of most advocacy should ultimately be self-advocacy (see Brandon, 1995; Braye and Preston-Shoot, 1995; Dalrymple, 2003; Goodley, 2000). Yet advocacy also encompasses collective action that seeks to challenge injustice and/or influence events at a more systemic level. Essentially, there are two modes of advocacy - individual case-based and cause-based, the former more engaged with concerns raised by individuals, the latter seeking to generate systemic change but often informed by cased-based issues (see Dalrymple, 2003, 2004b; Dalrymple and Hough, 1995; Henderson and Pochin, 2001). It has been demonstrated (Pithouse and Parry, 2005) that the predominant model commissioned by local authorities from national voluntary children's services across Wales is a service model (via service level agreement) that provides mainly case-based support to children looked after and children in need in the community. It is to a much lesser extent that these services promote cause advocacy that might contribute to system change locally or nationally.

\section{Research methods and protocols}

The methods used to identify (a) the number and characteristics of children's complaints involving advocacy and (b) the views of children about the complaints process and the role of advocacy included the following:

- A pre-tested survey instrument sent to all 22 local authorities in Wales about the characteristics of complaints in the financial year 2003/2004 involving children and local professional advocacy provision for children. All 22 responded to the survey and were able to provide data on the involvement of advocacy service, number of complaints, type of complaint, care status, age and gender of child and other categories concerning disability, ethnicity and language. Not all were able to indicate if the children's peers 
had acted as advocates. One authority was unable to indicate if a complaint was childled or adult-led. For reasons of economy the survey instrument was not designed to capture child-specific categories such as living in an area of poverty, immigration status, religion or ethnic sub-group - variables often associated with disadvantage and erosion of rights (Children's Rights Development Unit, 1994). Information on language, disability, and membership of Black or minority ethnic community was requested. It is also important to note that while advocacy providers may support children in making a complaint, this may not always be known to social services. Hence, where advocacy is cited by a local authority as being involved, this may refer only to those cases where advocates communicate to them their interest (by telephone, letter, or attendance at meetings) but the authorities may not necessarily know about other, less visible support for a complaint by advocacy providers.

- Audio-taped structured interviews with key professionals in all authorities who had been designated to deal with children's complaints, seeking their views on complaints procedures and the role of local advocacy services in supporting children.

- Analysis of secondary material on advocacy gathered from advocacy providers and respective commissioning local authorities (e.g. advocacy activity monitoring reports, quarterly reports from advocacy services to local authorities, local authority annual reports on complaints, service level agreements).

- Audio-taped semi-structured interviews were sought with a purposive sample of 25 children and young people known to social services and advocacy providers, who had been involved in a complaint during the previous 24 months ( 25 were identified but two withdrew before the interviews). Access to the children was mediated by the five national voluntary advocacy providers that between them covered all regions of Wales. Each agency was requested to provide us with a list of all their users (together with their background details: gender, age and care status at time of complaint, ethnicity, language, disability) who had made a complaint in the time period and were still contactable and willing to participate. A total of 114 were listed. From this population some 55 were identified by advocacy providers as still contactable and likely participants. From this 55, we selected five from each advocacy provider, thereby locating 25 young people from across all regions of Wales who had made complaints to social services.

Our eventual purposive but non probable sample, did reflect key characteristics contained in the total population of those making a complaint in the last two years in respect of their gender balance, their age range, whether they were looked after away from home or living at home, their disability status and their ethnicity. There were 14 females and nine males. Eight were aged 17-24 years; 10 were aged 14-16 years and five were between 10 and 13 years. Younger children were either not contactable or not willing to participate. Two-thirds were being looked after and a third were living at home with parents or living independently (three were care leavers). Nine were in foster care and six were living in children's homes (three were placed out of their local authority area). Three described themselves as Black British, the remainder were White Welsh. All but two were first language English speakers. Three were known to have a learning and/or physical disability. The interviews were guided by protocols around informed consent, participation, anonymity and safeguarding (Fraser and others, 2004; Kirby and others, 2003; Lewis and others, 2004). Transcripts were analysed using the constant comparative method (Silverman, 2005) and key categories arising from this are outlined below. In line with good practice, feedback was given to children about the common themes arising from the interviews. 


\section{Complaints involving children and young people in Wales}

All local authority social services in Wales were requested to complete a survey instrument in relation to their activity during the financial year 2003/2004 at complaints stages 1,2 and 3. These stages (as contained in The Children Act 1989 Guidance and Regulations, Volume 3-Family Placement and Volume 4 - Residential Care, Department of Health 1991) were defined for the purposes of the survey as stage 1 (problem solving or local resolution and formally noted as such); stage 2 (formal complaint involving investigation by named individual with reporting requirements); stage 3 (panel meeting involving independent members with reporting requirements). The Children Act, 1989 and associated guidance also requires local authorities to produce annual reports on complaints activity involving children.

\section{Stage 1 complaints}

The survey returns indicated a total of 611 stage 1 complaints involving children and young people during the year 2003/2004. Of these, 20 complaints were included in returns but without any details of whether these were adult- or child-led. A majority of stage 1 complaints involving children are led by adults, mainly kin ( $n=390$ or $64 \%$ ), almost double those led by children and young people ( $n=201$ or 33\%). Of these 611 stage 1 complaints, we can note that less than a half $(43 \%, n=264)$, involved children looked after. Of these 264 complaints, some 38 per cent $(n=101)$ involved children fostered in the local authority area; 44 per cent ( $n=116)$ involved children in residential care in the local authority area; 9 per cent $(n=23)$ involved children fostered or in residential settings placed out of the local authority area and another 9 per cent $(n=24)$ where children were defined as looked after but were living independently or with kin or friends. Here, we might note that 70 per cent of the 4315 children looked after children in Wales at 31 March 2004 were in foster placements and only 6 per cent were placed in residential care (Welsh Assembly Government, 2004). This does suggest a disproportionate number of complaints from those in residential care in the year in question. This is likely to be due, in part, to the high number of complaints (59) in one large urban authority where most children in residential care were known to have demonstrated their shared disapproval of local authority policy changes by making a complaint. Other reasons might include the possibility (although our study did not seek evidence for this) that advocacy providers find something of an accessible captive population in residential care as opposed to a widely dispersed clientele in foster care. Thus, those in residential care may be better informed and supported in bringing grievances or concerns to notice via complaints systems.

Most stage 1 complaints concern older age groups, approximately 311 for those aged $10+$ years compared with those aged 0-9 years. With stage 1 complaints, we can also note that a sizeable minority of the 611 complaints involve children not looked after $(n=144$, $24 \%$ ), living at home with kin (mainly parents), other carers or friends in the area. A very few complaints $(n=4,0.6 \%)$ involve local children living with kin or friends based outside their local authority area. The diversity of need in relation to advocacy has long been recognised (Herbert and Mould, 1992) but in respect of complaints the main social divisions seem to collect around White Welsh children who are looked after or are children living at home with kin. 
Overall, one Welsh speaker was identified across all the survey returns. Less than 5 per cent $(n=26)$ of complaints were known to involve children registered as disabled, according to the returns. Less than 3 per cent $(n=15)$ of complaints were identified as linked to Black and minority ethnic communities, not dissimilar to proportions in the wider population.

If we are to assume that children find the complaints process challenging (Wallis and Frost, 1998), then we might expect to see more use of professional advocacy funded by local government in Wales. Yet, when looking at the children's involvement with some type of local authority-funded professional advocacy in relation to these 611 complaints, the returns indicate some $63(10 \%)$ complaints involved such a service. Of these 63 complaints, 40 involved children leading their own complaint with professional advocacy support. In addition, there was a small cluster of nine (2\%) complaints involving children and young people who led their complaint but were supported by other professionals (such as a teacher, health professional or drugs and alcohol voluntary worker) acting as an advocate. The survey returns provided no information on any peer support children and young people may have received in leading a complaint.

Some 138 (23\%) complaints (of which 113 involved children looked after) were led by a young person (most aged 13+ years) without support from any adult. Whether this proportion of child-led complaints without support is somehow indicative of a facilitative complaints system that makes advocacy unnecessary or whether it reflects a lack of accessibility to advocacy by children and professionals (see Aiers and Kettle, 1998) is not something we can determine from the survey returns alone. However, our interviews with children would suggest difficulties in accessing advocacy - a point we discuss later.

\section{Stage 2 complaints}

As complaints become more formalised at stage 2 they reduce in number $(n=57)$; on average around two to three per authority for the year in question. They are much less likely to be led by children and much more likely to be led by adult kin $(70 \%, n=40)$. Overall, four of five complaints were led by kin and/or professional advocates. Most children involved were $10+$ years old. Unlike stage 1 complaints, there were more complaints involving children living in the local area with kin or friends $(n=47,81 \%)$. There were eight complaints in regard to children in foster care, one for a child in residential care (out of local area) and one for a child in independent living (out of local area), thus, 10 in all who were looked after (19\% compared with 43\% at stage 1). There were, proportionately, slightly more complaints involving children registered as disabled at stage $2(n=5,9 \%)$ than in stage 1 ( $n=26,5 \%)$, but the number overall are small and comparing them may be unwise. One Welsh speaker was identified. No children from minority ethnic communities were noted in the survey returns.

Proportionately, more cases at stage $2(25 \% n=14)$ compared with stage $1(10 \% n=63)$ involved support from local authority funded advocacy services. There were, proportionately, more children who led in these complaints and got support from local authority funded advocacy providers at this stage $(19 \%, n=11$ compared with $7 \%, n=42$ at stage 1$)$. A very few children advocated for themselves alone at this stage $(n=3,5 \%$ compared with $23 \%$ at stage 1 ). 
Thus, we can note that at stage 2 it is typically the case that adult kin have taken forward the complaint involving a child who is living in the local area with them or other kin or friends. We were unable to identify the likely causes of this pattern of complaints at stage 2, particularly the decrease in the involvement of looked after children at this stage compared with stage 1 . Whether this means that children looked after are less likely to find their complaints heard at stage 2 because they have no adult kin to motivate a complaint, compared to children living at home, and whether this implies some disadvantage for children in foster or residential care are questions we cannot answer in this study.

\section{Stage 3 complaints}

Once we arrive at stage 3 in which panels convene to examine complaints, we see very few cases and these are all led on behalf of children, mostly living at home, by adult kin. The survey data for stage 3 revealed 10 complaints in 2003/2004 across the whole of Wales. Most authorities reported nil cases. None reported more than one case. Of the 10 cases, two were linked to a local authority funded advocacy service. The small numbers allow no useful comparison, apart from noting the low incidence of complaints at this stage and the pivotal role of adult kin.

Across all complaint stages $(n=678)$, we can note the apparent low use of a professional advocacy service reported by local authorities (around 12\%, n=79) and the greater involvement of adult kin and self-advocacy (although the authorities, of course, may not always know about or accurately record advocacy activity). Overall, adult kin were more likely to lead complaints involving children throughout all stages. This adult-led pattern of complaints could be the outcome of complex processes that may include adult/professional views of children as recipients of services, 'self-evidently' lacking competence (see Mayall, 2002) and needing an adult voice to be represented. It may also reflect a lack of knowledge by children about advocacy as well as their reluctance to complain (Aiers and Kettle, 1998). There are likely to be organisational influences too, whereby advocacy is not recommended to children by professionals or agencies reluctant to become the object of critical attention (Boylan and Wyllie, 1999; Dalrymple, 2004a). Moreover, advocacy services may not always be sufficiently pro-active in selling their service (Pithouse and others, 2005). We will explore some of these possibilities soon, but first we outline the reasons for the above complaints.

\section{Themes within complaints involving children}

As part of the survey instrument, we asked local authorities to complete an open-ended section that asked them to identify the outline reasons, as formally determined by the complaints procedure, for each complaint and to cluster these where appropriate as child- or adult-led. Our analysis of their responses rarely allowed for coding into discrete and inclusive categories in which most complaints might typically fall. The complaints were frequently multi-issue and complex in their genesis and resolution, reflecting a weave of primary and secondary concerns threading back and forth across time and place. Hence, we avoided a league table comparative analysis of complaints across authorities, as this would denote an overly realist assumption that the quantity and type of complaints can somehow be a proxy measure of poor or good perform- 
ance by social services (for example, authorities with accessible and well-supported complaints systems might well generate more complaints than authorities that resist complaints and/or seek to avoid codifying issues as complaints by dealing with them outside formal procedures where possible). That said, it was possible to detect key themes and qualitative differences in regard to child- or adult-led complaints. In respect of child-led complaints we noted they collected into four distinct and sometimes overlapping domains:

- Concerns in relation to foster care, leaving care and placements appeared to be more often led by children and comprised the areas where most of their complaints were located.

- Concerns in relation to contact between children looked after and their parents, kin or significant others also appeared to be prominently represented in child-led complaints.

- Concerns over relatively a few instances $(<5)$ in survey returns about looked after children being subjected to bullying by other children, or about the behaviour of other service users, were led by children.

- Concerns in relation to ineffective communication between the local authority and service users over decisions was a notable cluster and seemed to be as often raised by children as by adults.

Children were more likely to complain in relation to matters of personal care, contact with kin and effective communication with staff - seemingly more to do with the emotional and relational side of care and wellbeing. By contrast, adult-led complaints involving children collected more around the appropriateness or quality of provision, decision-making, the perceived attitude/conduct of staff and the accuracy or negative tone of records/minutes of meetings. Adults were more likely than children to challenge allegations by social services about abuse or neglect. Disability-related matters were also likely to be led by adults. Children's complaints, perhaps predictably, seem to connect to some unhappiness about how or where they are being cared for and their relationship with significant others. As in Waterhouse (2000), their vulnerability and their resilience were evident in their recollections about making a complaint, as we discuss next.

\section{Children's views of the complaints process}

We suggest that complaints, like other organisational processes in social work, reflect a view of childhood and children that can appear ambivalent, revealing both controlling and empowering elements in the way children and parents are viewed as culpable or innocent of the problems that bring them to notice (see Goldson, 2001; Wattam and Parton, 1999). Thus, we should not be surprised to find that the way children and young people describe their experiences of complaints reflects their recollection of the way key professionals treated them with (or without) positive regard and effective support in responding to those matters they raised (see Aiers and Kettle, 1998; Barford and Wattam, 1991).

The interviews revealed that young people have a range of agencies involved in their lives and may need support to access complaints procedures. In respect of social services, young people did not recall being given relevant information about the different stages of the complaints process. Their views also suggest that informal complaints (stage 1) are not always 
encoded as such at the outset by some authorities, who seemed to respondents to be playing for time in the hope that matters could somehow be resolved without officially recording the issue. In a minority of cases, this led to lengthy periods in dealing with their concerns as well as evident confusion for young people over the status of the matters they had raised.

Complaints procedures and terminology are likely to be adult-designed and can be daunting to young service users (see Wallis and Frost, 1998); thus it may not be surprising to note that the views of most respondents suggested a lack of clarity about the roles and the rights of young people to progress the full complaints process. When describing what motivated them to complain to the social services, most stated it was 'not being listened to' or 'not taken seriously'. All the young people interviewed stated they had tried repeatedly to get their concerns dealt with by social services and felt that the staff had not given due weight to the issues they raised. The young people claimed they often struggled to get answers from the social services to apparently simple questions about what help or support they were entitled to. These responses find common ground with the relatively few studies into why children complain to the social services and which point to the way in which some professionals construct children as having marginal status and a limited capacity to be self-determining, and whose views are thereby less significant (see Dalrymple, 2004a; Dalrymple and Hough, 1995).

\section{Access to the complaints procedure}

While the respondents became aware at some point that they had a right to complain, they still lacked information (and more importantly, explanations) about how to complain and what they could expect to happen as a result. A third of the respondents found out about their right to complain from the adults around them (mainly social services staff). In some cases, this was combined with knowledge gained from a leaflet, poster or card. A third of the respondents found out about their rights to complain, how to do it and what the complaints process was, through an advocacy service. Some young people thought that the adults responsible for young people's care should do more to promote their knowledge of, and rights to, making a complaint.

Regular mailings and information from local authority complaints officers directed to those looked after or receiving services did reach our respondents. Most, however, struggled to make sense of this information and felt it did not tell them enough about the procedure and what to expect (see also Aiers and Kettle, 1998). The information did not respond to the young people's concerns about using the procedure, for example the lack of trust in social services by some and/or their fear of repercussions. A few young people understood what would happen when they made a complaint. Information about how young people would be kept informed and could participate in the process was considered to be unclear. Many young people remained unclear about the process they and their complaint had gone through, even after they had completed the process. Initial delays of six weeks or more in responding in writing to complaints were reported by half our interviewees.

\section{Support and advocacy}

The qualities that children and young people enjoy in relation to advocacy support are well documented (Noon, 2000); however, they first have to find out where such services can be 
found. Guidance on where to find support and advocacy was not always offered to our respondents when they first decided on making a complaint. Children's complaints officers, social workers and other care professionals were pro-active in helping a third of respondents gain support from advocacy. Independent advocacy, where used by respondents, was said to be easy to access when its existence was made known; many would have liked to have had such support earlier.

As with Barford and Wattam (1991) and Dalrymple (2004a,b), some respondents recognised that their social workers and others (such as children's complaints officers), were employees of the local authority and not independent professionals able to advocate robustly for them. Yet interestingly, where local authority complaints officers were committed to making the process children-friendly, then independent support was not always seen as essential or preferred. Moreover, it was the case that a small number of respondents saw the advocacy service funded by the local authority as lacking independence because of this financial relationship.

Generally, independence and distance from the local authority was important for many young people. They valued independent services for giving them time, resources and information, for listening to them, and for support and staying with them throughout the process - key characteristics of a good advocate (see Noon, 2000). Those who used advocacy services indicated that they found invaluable the practical and emotional help they received in negotiating the complaints procedure. The sense of close involvement by an advocate in helping the complaint progress was a key determinant in the young people's overall satisfaction with the process of making a complaint. The respondents tended to view the relationship as almost one of friendship, and for that reason quite different from their relationships with other care professionals. What is of note here is not simply the theme of affect as defining the advocacy relationship but rather a relationship built on a more equal and, in their view, respectful basis wherein time and a willingness to listen was not in short supply (see also Dalrymple, 2004b).

Children and young people need practical help in getting their voice heard but without their views being moderated or transformed in some way by an advocate (see Templeton and Kemmis, 1998). For our respondents, writing a letter, often with the support of an advocate, was the most common way of young people registering their complaint. For most of our respondents this was done after making verbal complaints to local authority staff on a number of occasions and not gaining a response, or the response anticipated. Again, this raises concerns about whether social workers and/or carers are acknowledging stage 1 complaints. A strong impression gained was of young people and their advocates driving the complaints procedure, rather than the process being facilitated by social services. Young people frequently perceived advocates to be pushing the local authority to take their complaint seriously. Most respondents recalled that they had tried to get their concerns resolved through other less formal channels.

Vulnerable young people need a professional to act on their behalf with vigour and determination (Cleaver, 1996, p. 24). In relation to the local authority complaints officer, we can note that complaints were more likely to be treated as such, kept to time and purpose and respecting young people's rights when a pro-active, interested complaints officer was involved. By contrast, only a few young people spoke positively about the role their social worker had played in encouraging them to make a complaint. In general, the young people were critical of the service they received from their social worker (or their lack of a social 
worker). For over a fifth of respondents, it was their social worker and the service they received that was the basis of their complaint. The role of the social worker as an advocate for their client was largely absent from the young people's perspective.

\section{The complaints procedure - satisfaction and perceived outcomes}

Our sample does not permit claims to be made about a wider population of children involved with the social services and complaints systems. That said, we can observe that a half of those interviewed were satisfied with the complaints process, approximately a third were dissatisfied and the rest were neither satisfied nor dissatisfied. Over half of the young people interviewed (13) received decisions on their complaints within the time framework recommended by legislation. Of 17 young people whose complaints had concluded, 10 were satisfied with the outcome; three were not and four neither dissatisfied nor satisfied. Overall, nearly three-quarters (18) thought it had been worthwhile making a complaint to the local authority; two young people had mixed feelings about it and three said using the complaints procedure had not been worthwhile. While it is encouraging to note these positive responses it is still the case, as with earlier studies (Aiers and Kettle, 1998; Wallis and Frost, 1998), that young people feel it is hard to raise concerns and make a complaint. While key reports (Clarke, 2003; Waterhouse, 2000) urge authorities to give clear messages that those who make complaints should not fear repercussions, it was nonetheless the view of several respondents that such fears were part of what makes it hard for some young people to raise concerns.

\section{Key messages for advocacy}

While children and young people spoke positively about advocacy they also thought it needed to be more accessible and visible. Leaflets and written information were often not read and/or retained by young people. More innovative multi-setting and multi-media approaches were suggested. Young people were appreciative of advocacy in relation to their complaints. Most complaints to social services involving children were led by adults (mainly kin). Most complaints got resolved at the early, more informal, stage of investigation. Most complaints that moved to stages 2 and 3 involved children living with their family or others in the community relatively few complaints at these more formal stages involved children who were (at that point) looked after. Relatively few complaints across all stages were described as involving support from professional advocacy services.

Interviews with the children involved in a complaint indicated that most found the experience to be worthwhile. The majority of young people had suggestions for how their experience of making a complaint could have been improved upon. This included key professionals (particularly social care staff) taking a more pro-active support role; raising young people's awareness through child-appropriate information; providing better access to independent support and speeding up the length of time to get a decision. The young people suggested that a commitment to lay and professional education, information, support, and an effective and positive approach to listening to and resolving complaints needs to be put in place if children and young people are to be encouraged, rather than put off, by the complaints process. 
Several young people described with affection the role of the children's (or similarly designated) complaints officer in social services in the way that complaint procedures and processes were understood as meaningful and responsive; and the way that advocacy was introduced and mediated to the complainant and to those professionals in the service complained about. The role of complaints officer is not well researched but some preliminary observations about their status and authority (see Pithouse and others, 2005) would suggest that, while they can have a considerable impact on children's experience of complaints, they are unlikely to have the power to challenge prevailing organisational discourses about risk management and protection in children's services and the ambivalence towards advocacy therein (see Dalrymple, 2004a; Wattam and Parton, 1999). The issue about promoting the child's voice via advocacy is not reducible simply to enhancing some particular role but more a matter of system change. Children in Wales, as we have seen from their involvement in complaints, are bound up in a system where advocacy seems to play a relatively marginal part. They are also in a system where children experience difficulties in accessing advocacy and where many are their own sole advocate. For most children their adult kin lead in making a complaint and it is possible that their respective agendas are not synonymous.

We take these findings to suggest the need for a significant shift in attitudes towards the rights of children and young people and their use of advocacy. Our study has helped inform Welsh government policy deliberations that now envisage a major change in delivering advocacy whereby its role is extended beyond children in need and widened to cover all key services that promote children's welfare. One option being considered is for key providers of children's services (education, health and social services) to combine in regional consortia and to commission a more inclusive advocacy service that can support all the children and young people they serve. This would reconfigure advocacy across a wider constituency of interest and loosen its current association with child protection, children looked after and children with a disability as the main or only recipients of advocacy involvement. Mainstreaming advocacy in this way would stem from and connect with a children's rights discourse that seeks to promote a view of children as children and citizens first, and not defined solely by their vulnerability. Shifting the balance of complaints and advocacy from a narrow adult-oriented focus around welfare issues to a more child-centred and child-led process that promotes authentic voice and rights would be a benchmark of civic and institutional progress as well as something our children and young people should grow up expecting. We shall see.

\section{References}

Aiers A, Kettle J. 1998. When Things Go Wrong: Young People's Experience of Getting Access to the Complaints Procedure in Residential Care. National Institute for Social Work: London.

Barford R, Wattam C. 1991. Children's participation in decision-making. Practice 5: 93-101.

Boylan J, Wyllie J. 1999. Advocacy and child protection. In Child Sexual Abuse: Responding to the Experiences of Children. Parton N, Wattam C (eds). Wiley: Chichester; 56-70.

Brandon D. 1995. Peer support and advocacy: international comparisons and development. In Empowerment in Community Care. Jack R (ed.) Open University Press: Buckingham.

Braye S, Preston-Shoot M. 1995. Empowering Practice in Social Care. Open University Press: Buckingham. Carlile L. 2002. Too Serious A Thing: Review of Safeguards for Children and Young People Treated and Cared For by the NHS in Wales. National Assembly for Wales: Cardiff.

Children's Rights Development Unit. 1994. Agenda for Children. CRDU: London. 
Clarke P. 2003. Telling Concerns: Report of the Children's Commissioner for Wales Review of the Operation of Complaints and Representations and Whistleblowing Procedures and Arrangements for the provision of Children's Advocacy Services. Office of Children's Commissioner for Wales: Swansea.

Cleaver H. 1996. Focus on Teenagers: Research into Practice. HMSO: London.

Dalrymple J. 2003. Professional advocacy as a force for resistance in child welfare. British Journal of Social Work 33: 1043-1062.

Dalrymple J. 2004a. Constructions of child and youth advocacy: emerging issues in advocacy practice. Children \&t Society 19: 3-15.

Dalrymple J. 2004b. Developing the concept of professional advocacy: an examination of the role of child and youth advocates in England and Wales. Journal of Social Work 4: 181-199.

Dalrymple J, Hough J. (eds). 1995. Having a Voice: An Exploration of Children's Rights and Advocacy. Venture Press: Birmingham.

Department of Health. 1991. The Children Act 1989 Guidance and Regulations, vol. 3, Family Placement, vol. 4. Residential Care. Department of Health: London.

Department of Health. 2003. National Standards for the Provision of Children's Advocacy Services. Department of Health: London.

Fraser S, Lewis V, Ding S, Kellett M, Robertson C. (eds). 2004. Doing Research with Children and Young People. Sage: London.

Goldson B. 2001. The demonisation of children. In Children in Society: Contemporary Theory, Policy and Practice. Foley P, Roche J, Tucker S (eds). Palgrave: Basingstoke; 34-41.

Goodley D. 2000. Self Advocacy in the Lives of People with Learning Difficulties. Open University Press: Buckingham.

Henderson R, Pochin M. 2001. A Right Result? Advocacy Justice and Empowerment. Policy Press: Bristol.

Herbert M, Mould J. 1992. The advocacy role in public child welfare. Child Welfare 71: 114-130.

Jones A. 1999. Report of the Examination Team on Child Care Procedures and Practice in North Wales. HMSO: London.

Kirby P, Lanyon C, Cronin K, Sinclair R. 2003. Building a Culture of Participation: Involving Children and Young People in Policy, Service Planning, Delivery and Evaluation. National Children's Bureau and PK Research Consultancy: London.

Lewis V, Fraser S, Ding S, Kellett M, Robertson C. (eds). 2004. The Reality of Research with Children and Young People. Sage: London.

Mayall B. 2002. Towards a Sociology of Childhood: Thinking from Children's Lives. Open University: Buckingham.

Noon A. 2000. Having a Say: The Participation of Children and Young People at Child Protection Meetings and the Role of Advocacy. The Children's Society: London.

Pithouse A, Parry 0. 2005. Children's advocacy in Wales - organisational challenges for those who commission and deliver advocacy for children who are looked after. Journal of Adoption and Fostering 29: 45-56.

Pithouse A, Crowley A, Parry 0, Payne H, Dalrymple J. 2005. A Study of Advocacy Services for Children and Young People in Wales: A Key Messages Report. Cardiff University School of Social Sciences, Social Inclusion Research Unit University of North East Wales, Department of Child Health, Wales College of Medicine: Cardiff.

Silverman D. 2005. Doing Qualitative Research, 2nd edn. Sage: London.

Templeton J, Kemmis J. 1998. How Do Young People and Children Get Their Voices Heard? Voice for the Child in Care: London.

Utting W. 1997. People Like Us: The Report of the Review of the Safeguards for Children Living Away from Home. Stationery Office: London.

Wallis L, Frost N. 1998. Cause for Complaint: The Complaints Procedure for Young People in Care. Children's Society: London.

Waterhouse R. 2000. Lost in Care: Report of the Tribunal on Inquiry into Abuse of Children in Care in the Former County Council Areas of Gwynedd and Clwydd. HMSO: London.

Wattam C, Parton N. 1999. Impediments to implementing a child centred approach. In Child Sexual Abuse: Responding to the Experiences of Children. Parton N, Wattam C (eds). Wiley: Chichester; 1-18. 
Welsh Assembly Government. 2003a. Providing Effective Advocacy Services for Children Making a Complaint. WAG (October): Cardiff.

Welsh Assembly Government. 2003b. National Standards for the Provision of Children's Advocacy Services. WAG (February): Cardiff.

Welsh Assembly Government. 2004. Personal Social Services Statistics Wales 2003-4. Local Government Data Unit - Wales: Cardiff.

${ }^{*}$ Correspondence to: Andrew Pithouse, Childhood Research Group, School of Social Sciences, Cardiff University, King Edward V11 Avenue, Cardiff CF10 3WT, UK. E-mail: pithouse@cardiff.ac.uk

Accepted date: 28 June 2006

\section{Contributors' details}

Andy Pithouse is a professor in the Cardiff School of Social Sciences Childhood Studies Research Group. He teaches on the social work programme and undertakes research mainly in child and family services.

Anne Crowley is a freelance researcher, trainer and policy consultant in children's services and parttime research officer for Save the Children (Wales). 